\title{
Source contributions and mass loadings for chemicals of emerging concern: Chemometric application of pharmaco-signature in different aquatic systems
}

Jheng-Jie Jiang ${ }^{1,3}$, Chon-Lin Lee ${ }^{1,2,3,4, *}$, Peter Brimblecombe ${ }^{5}$, Lucie Vydrova ${ }^{6}$, Meng-Der Fang ${ }^{7}$

${ }^{1}$ Department of Marine Environment and Engineering, National Sun Yat-sen University, Kaohsiung, Taiwan

${ }^{2}$ Department of Public Health, College of Health Science, Kaohsiung Medical University, Kaohsiung, Taiwan

${ }^{3}$ Asia-Pacific Ocean Research Center, National Sun Yat-sen University, Kaohsiung, Taiwan

${ }^{4}$ Research Center of Environmental Medicine, Kaohsiung Medical University, Kaohsiung, Taiwan

${ }^{5}$ School of Energy and Environment, City University of Hong Kong, Kowloon, Hong Kong, China

${ }^{6}$ Faculty of chemistry, Brno University of Technology, Brno, Czech Republic

${ }^{7}$ Green Energy and Environment Research, Industrial Technology Research Institute, Hsinchu, Taiwan

* Corresponding author: Department of Marine Environment and Engineering, National Sun Yat-sen University, 70 Lienhai Rd., Kaohsiung 80424, Taiwan Tel.: +886 75252000 ext. 5066; Fax: +886 75255066

E-mail address:

jjjiang@mail.nsysu.edu.tw (JJ Jiang)

linnohc@mail.nsysu.edu.tw (CL Lee)

P.Brimblecombe@uea.ac.uk (P. Brimblecombe)

vydrova@fch.vutbr.cz (L.Vydrova)

damonder@itri.org.tw (MD Fang) 


\section{Abstract}

To characterize the source contributions of chemicals of emerging concern (CECs) from different aquatic environments of Taiwan, we collected water samples from different aquatic systems, which were screened for 30 pharmaceuticals and illicit drugs. The total estimated mass loadings of CECs were $23.1 \mathrm{~g} / \mathrm{d}$ in southern aquatic systems and $133 \mathrm{~g} / \mathrm{d}$ in central aquatic systems. We developed an analytical framework combining pollutant fingerprinting, hierarchical cluster analysis (HCA), and principal component analysis with multiple linear regression (PCA-MLR) to infer the pharmaco-signature and source contributions. Based on this approach, we estimate source contributions of $62.2 \%$ for domestic inputs, $16.9 \%$ for antibiotics application, and $20.9 \%$ for drug abuse/medication in southern aquatic system, compared with $47.3 \%$ domestic, $35.1 \%$ antibiotic, and $17.6 \%$ drug abuse/medication inputs to central aquatic systems. The proposed pharmaco-signature method provides initial insights into the profile and source apportionment of CECs in complex aquatic systems, which are of importance for environmental management.

Capsule: The proposed pharmaco-signature method provides initial insights into the profile and source apportionment of CECs in complex aquatic systems.

Keywords: Source apportionment; emerging contaminants; fingerprinting; mass loading; risk quotient. 


\section{Introduction}

The contamination of freshwater ecosystems by synthetic chemicals is increasing worldwide. As the global population increases and economies in many regions show considerable growth, the production of chemicals is also predicted to increase. Anthropogenic compounds, such as pharmaceuticals, antibiotics, UV filters, and illicit drugs, are collectively referred to as chemicals of emerging concern (CECs). Due to their large production volumes and continuous usage, some of these compounds have become "pseudo-persistent" in the environment (Hernando et al., 2006; Postigo et al., 2010). The occurrence of these compounds has been reported in most aquatic systems (Jiang et al., 2014; Loos et al., 2013; Luo et al., 2014; Vidal-Dorsch et al., 2012). Although CECs usually occur at low environmental concentrations, many are of toxicological concern, particularly when they occur with the combined effects of multiple contaminants (Hoerger et al., 2014; Schwarzenbach et al., 2006); consequently, the potential environmental risks of residual CECs should not be ignored.

Despite treatment, the wastewater from households and industry is a major source of CECs entering the aquatic environment (Michael et al., 2013; Phillips et al., 2010). Additionally, untreated wastewater can also be discharged via sewer overflow or leaks. As a consequence of these sources and pathways for CECs, many can be found in freshwater ecosystems, particularly in densely populated regions (Heeb et al., 2012). Attention has generally been focused on investigating the occurrence and behavior of CECs in aquatic environments (Bu et al., 2013; 
Carmona et al., 2014; Gonzalez et al., 2012; Hoerger et al., 2014; Verlicchi et al., 2012; Xue et al., 2013). However, available information on the sources and mass loadings of CECs in densely populated regions remains very limited, especially for the megacities in Taiwan, which is the $17^{\text {th }}$ most densely populated country globally (647 people $\mathrm{km}^{-2}$ ), with a population of 23 million (UNWPP, 2013).

With appropriate analysis, pollutant profiles reflect the present CEC status of particular water sources and can infer pharmaco-signature and relative contributions. The present study addresses the challenge of accounting for source contribution of CECs by characterizing their fingerprint in aquatic systems. The purpose of this study is to: (1) examine the occurrence and spatial patterns of common CECs, (2) investigate mass loadings of CECs in different aquatic systems, and assess associated ecological risks via risk quotients (RQs), and (3) demonstrate and compare significant source contributions and the pharmaco-signatures of CECs via multivariate analysis including unsupervised pattern recognition (hierarchical cluster analysis, HCA) and receptor model (principal component analysis-multiple linear regression, PCA-MLR) in different aquatic systems. The results indicate that the proposed method can reliably estimate source contribution of CECs in aquatic environments.

\section{Material and methods}

\subsection{Chemicals and standards}

Thirty CECs, including analgesics, antibiotics, lipid regulators, $\beta$-blockers, antiepileptic drugs, psychostimulants, ulcer healing compounds, UV filters, and 
illicit drugs, were selected as target compounds. Most of the selected CECs are frequently used in prescriptions, over-the-counter medications, human treatments, veterinary medicines, and illicit drugs in Taiwan. These CECs are also reported in many other researches worldwide (Jiang et al., 2014; Jiang et al., 2015b; Kasprzyk-Hordern et al., 2008; Kolpin et al., 2002; Nakada et al., 2007; Thomas et al., 2012; Yoon et al., 2010; Zhu et al., 2013). The chemicals and standards used in this study (including suppliers, purities, and detailed physiochemical properties of the 30 target CECs) are described in section S1 and Table S1 of the Supplementary Information.

\subsection{Aquatic systems and sample collection}

Samples were collected from two aquatic systems in Taiwan (Table 1). The locations of the sampling sites are shown in Figure 1. In the southern aquatic system, we investigated three rivers and one canal in Tainan, which has a population of approximately 1.8 million and is located between the Yanshuei and Agongdian Rivers. The Yanshuei (Y1-Y6) and Erren Rivers (E1-E8) have drainage basins of 343.7 and $339.2 \mathrm{~km}^{2}$ and lengths of 41.3 and $61.2 \mathrm{~km}$, respectively. The Tainan Canal (C1-C5), which is $37 \mathrm{~m}$ in width and $5 \mathrm{~km}$ in length, flows through urban areas and is influenced mostly by domestic sewage. The Agongdian River (A1-A4) has a length of $38 \mathrm{~km}$ and a catchment area of $137 \mathrm{~km}^{2}$. The most upstream site, Agongdian Reservoir, (at the head of Agongdian River) was used as a control site (A1). This site was chosen as it had little human activity or contamination. In the central aquatic system, two main rivers, namely, the $\mathrm{Wu}$ 
(W1-W8) and Zhuoshui Rivers (Z1-Z7), were chosen to characterize the city of Taichung. The Wu River, with an overall length of $117 \mathrm{~km}$ and a drainage area of $2026 \mathrm{~km}^{2}$, flows through Taichung, which is the third most populous city in Taiwan (2.7 million inhabitants). Two small drainage systems (LIC and LYC), which receive direct discharges of domestic wastewater from surrounding residential areas, were also sampled. Constituting the longest river in Taiwan, the Zhuoshui River is a mountain stream (total length $187 \mathrm{~km}$ ) that drains an area of $3155 \mathrm{~km}^{2}$. From upstream to downstream, it flows through rural areas, industrial districts, agricultural, and animal husbandry areas. Detailed information on the sampling sites is given in Table S2 and Figure S1 of the Supplementary Information.

Forty samples were collected in the two aquatic systems during August (central aquatic system) and November (southern aquatic system) 2010. All of the samples were collected approximately $0-50 \mathrm{~cm}$ below the surface using a stainless steel bucket from bridges at the centroid of the flow. Samples were immediately transferred to 1-L amber glass bottles that had been pre-cleaned successively with detergent, distilled water, and methanol and finally dried. Each bottle was rinsed with sample water prior to sampling. The samples were kept at $4^{\circ} \mathrm{C}$ in a cold storage room before further treatment and analysis in the laboratory.

\subsection{Analytical methods}

The CECs were concentrated and analyzed using the following previously 
published method (Jiang et al., 2014; Jiang et al., 2015b). Briefly, 1-L water samples were filtered through $0.45-\mu \mathrm{m}$ glass fiber filters and then acidified to $\mathrm{pH}$ 6.0. Subsequently, samples were passed through HLB solid-phase extraction (SPE) cartridges and each cartridge was then rinsed with $6 \mathrm{~mL}$ ultra-pure water and dried for 30 min using the vacuum of the SPE manifold. After drying, the cartridge was eluted with $6 \mathrm{~mL}$ methanol. More details about the sample extraction procedures are described in the Supplementary Information.

A liquid chromatograph-electrospray ionization tandem mass spectrometry (LC-ESI-MS-MS) system with multiple reaction monitoring (MRM) was used to analyze the extracted CECs (MRM mode, using two of the highest characteristic precursor ion/production ion transitions). Two different methods were applied for the separation of analytes (method 1 for pharmaceuticals, antibiotics, and UV filters; method 2 for illicit drugs) and both were performed using an Agilent 1200 series chromatograph (Agilent, Palo Alto, CA, USA) interfaced with an API 4000 triple quadrupole mass spectrometer (Applied Biosystems, Foster City, CA) operated in ESI positive and negative modes. The injection volumes for method 1 and method 2 were 50 and $10 \mu \mathrm{L}$ respectively, and the auto-sampler was operated at $25^{\circ} \mathrm{C}$. The gradients and mass spectrometer conditions are described in the section S1 and Tables S3-S4 of the Supplementary Information.

\subsection{Quality analysis and quality control}

For all the compounds, wide linearity ranges were obtained for the quantification. Seven to ten points' calibration curves were constructed using 
least-squares linear regression analysis, and subjecting them to the same SPE procedures used for the environmental water samples spiked with the analytes, typically from 0.5 to $2000 \mathrm{ng} / \mathrm{L}$ with $r^{2}>0.9991$ for all compounds. Recovery experiments were performed on DI water and river water samples spiked with $500 \mathrm{ng} / \mathrm{L}$ target analytes and isotopically labelled surrogates to estimate the precision, absolute recovery, and accuracy of the analytical method. Table S5 presents recoveries for the target analytes in DI water and river water. The mean recoveries in DI water ranged from $79 \%$ to $103 \%$, compared with $81 \%$ to $110 \%$ in river water, while mean recoveries of isotopically labeled surrogate standards were: $80 \pm 12 \%$ (acetaminophen- $\mathrm{d}_{4}$ ), $83 \pm 9 \%$ (amphetamine- $\mathrm{d}_{11}$ ), $82 \pm 13 \%$ (methamphetamine- $\mathrm{d}_{14}$ ), $81 \pm 11 \%$ (MDMA- $\mathrm{d}_{5}$ ), $95 \pm 7 \%\left({ }^{13} \mathrm{C}_{6}\right.$-ibuprofen), and $90 \pm 13 \%\left({ }^{13} \mathrm{C}_{3}\right.$-caffeine), respectively. The high recoveries of the added target analytes and isotopically labeled surrogates suggest that matrix effects were relatively minor. Field and procedural blanks were treated as controls for possible contamination in the laboratory and in field sampling. Analysis of these blanks demonstrated that the extraction and sampling procedures were free of contamination. The limits of detection (LOD) were defined as signal-to-noise $(\mathrm{S} / \mathrm{N})$ ratios of 3, and the limits of quantification (LOQ) were defined as signal-to-noise $(\mathrm{S} / \mathrm{N})$ ratios of 10 . The results indicated that the $\mathrm{LOQ}$ for each compound ranged from $0.25 \mathrm{ng} \mathrm{L}^{-1}$ to $4 \mathrm{ng} \mathrm{L}^{-1}$ for DI water, and from $0.75 \mathrm{ng} \mathrm{L}^{-1}$ to $5 \mathrm{ng} \mathrm{L}^{-1}$ for river water (Table S5). Overall, the validation data, such as repeatability, recoveries, and LOQ were good, so the reliable determination of these target compounds was feasible (Table S5). More details about quality 
analysis and quality control are described in the section S1 of the Supplementary Information.

\subsection{Statistical analysis}

In this work, hierarchical cluster analysis (HCA) was implemented in SPSS 16.0, using Ward's hierarchical agglomerative method of clustering and Euclidean distance measure, to analyze the relationships between chemical compounds. HCA is a statistical method to classify samples into clusters through their similarity and various cluster rules. Source contribution analysis was conducted using a principal component analysis-multiple linear regression (PCA-MLR) model. Concentrations of chemicals can be regarded as linear combinations of a number of factors (or sources), and the purpose of PCA is to reduce the correlation matrix to a minimum number of key factors. The concentrations were Kaiser-normalized and transformed via varimax rotation. Multiple linear regression (MLR) was then performed on the significant factors to determine the mass apportionment of each source to total concentrations. Stepwise modeling was used to incorporate each independent factor within the regression equation if it could significantly increase the correlation, and a default significant level of 0.05 was used. After normalization, the MLR equation can be expressed as Eq. 1.

$$
\hat{Z}_{\text {sum }}=B_{k} F S_{k}
$$

Where $\hat{Z}_{\text {sum }}$ is the standard normalized deviate of the sum of the chemical concentrations, $B_{k}$ represents the regression coefficients, and $F S_{k}$ are factor 
scores calculated by the PCA analysis. The mean percentage contribution can be

calculated from $B_{k} / \quad B_{k}$, and the contribution of each source $k$ was estimated as in Eq. 2.

$$
\text { Contribution of source } k(\mathrm{ng} \mathrm{L}-1)=\operatorname{mean}\left[Z_{\text {sum }}\right]\left(B_{k} / B_{k}\right)+B_{k} F S_{k}
$$

More information on the use of PCA-MLR in environmental studies is available in the literature (Chang et al., 2009; Hopke, 2003; Larsen and Baker, 2003).

\section{Results and discussion}

\subsection{Occurrence and distribution of CECs}

A total of twenty CEC compounds were detected in both the southern and central aquatic systems, including seven analgesics (acetaminophen, diclofenac, ibuprofen, ketoprofen, naproxen, salicylic acid, and codeine), four antibiotics (sulfamethoxazole, ampicillin, tetracycline, and erythromycin- $\mathrm{H}_{2} \mathrm{O}$ ), three illicit drugs (methamphetamine, ketamine, and pseudoephedrine), two UV filters (benzophenone-3 and benzophenone-4), two lipid regulators (clofibric acid and gemfibrozil), caffeine, and carbamazepine (Fig. 2). Since cocaine is usually highly metabolized, suggesting the main human metabolite (benzoylecgonine) should be further monitored. As expected, no CECs were detected at the Agongdian Reservoir control site (A1). In general, total CEC concentrations ranged from 15.1 to $2470 \mathrm{ng} \mathrm{L}^{-1}$ in the southern aquatic system and from 55.5 to $25800 \mathrm{ng} \mathrm{L}^{-1}$ in the central aquatic system. Pseudoephedrine was detected at all sampling sites in the southern aquatic system, while ibuprofen, ampicillin, and pseudoephedrine 
were detected in all samples from the central aquatic system. The high detection frequency and concentrations of pseudoephedrine are likely due to the large amount of this chemical used to treat acute hypertension, rhinitis, sinusitis, and depressive states in Taiwan (TWFDA). Caffeine was dominant among all target CECs in the southern (maximum concentration: $1143 \mathrm{ng} \mathrm{L}^{-1}$ ) and central (maximum concentration: $16640 \mathrm{ng} \mathrm{L}^{-1}$ ) aquatic systems. A global comparison of residual CEC levels in surface waters is listed in Table S6. The levels found in this study are generally lower than those reported in the US, but comparable to those from rivers in Japan, Korea, China, the UK, and Spain. These observed differences could be either characteristic of the sampling sites or due to general differences in prescribing patterns among countries.

Between the two aquatic systems, the drainage systems were the most contaminated, with a sum CEC concentration of $31985 \mathrm{ng} \mathrm{L}^{-1}$, following by the Wu River (14400 ng L-1), Tainan Canal (6770 ng L-1), Agongdian River (5994 ng $\mathrm{L}^{-1}$ ), Erren River (5667 ng L-1), Yanshuei River (4127 ng L-1), and Zhuoshui River (1069 ng L-1). Differences in CEC profiles were evident between residential and animal husbandry areas. For example, as shown in Figure 3, the mean concentrations of analgesics and caffeine in the aquatic systems of mixed-zone urban and suburban areas (Yanshuei River, Tainan Canal, Erren River, Agongdian River, Wu River, and Drainage systems) were noticeably higher than that of the Zhuoshui River, which may be a result of domestic discharges from the high population densities in these cities. On the other hand, it is obvious that animal husbandry has important impacts on antibiotic contamination of the Zhuoshui 
River in the central aquatic system. This was probably due to the fact that water courses draining into the Zhuoshui River run through the thriving animal husbandry areas of central Taiwan (COA).

\subsection{Mass loadings of CECs}

In our study, rivers can be identified as the main sources of CECs to the environments, although runoff and discharge of untreated waters cannot be neglected. But since temporal variability and precise data are not available, this contribution was not taken into consideration. To calculate the CEC mass loadings to the aquatic environments, the concentrations detected in the two water systems were considered in addition to the flow volume (Sanchez-Avila et al., 2012). The inputs to the aquatic environments were calculated according to:

$$
\begin{aligned}
& \text { Mass loadings }\left(\mathrm{g} \mathrm{d}^{-1}\right)=\left[\text { Mean concentration of CECs }\left(\mathrm{g} \mathrm{m}^{-3}\right)\right] \times \\
& {\left[\text { Flow of water }\left(\mathrm{m}^{3} \mathrm{~d}^{-1}\right)\right]}
\end{aligned}
$$

Figure 4 demonstrated the daily CEC mass loadings to the aquatic environments in different river systems. Although CEC concentrations in the Tainan Canal were much higher than in the rivers, detailed discharge data are unavailable, so mass loadings in the Tainan Canal could not be estimated. The results show that the southern aquatic system contributed a total CEC mass loading of $23.1 \mathrm{~g} \mathrm{~d}^{-1}$, and a total of $133 \mathrm{~g} \mathrm{~d}^{-1}$ was discharged into the central aquatic system. The inputs to the central aquatic system are several times higher than those estimated for the southern aquatic system; this is to be expected, since not only are the water flow rates considerably higher but also CEC 
concentrations were comparatively higher in the city of Taichung.

For the mass loadings in all aquatic systems, the four dominant CECs such as caffeine, ibuprofen, acetaminophen, and ampicillin were $62.2,18.1,14.8$, and $12.1 \mathrm{~g} \mathrm{~d}^{-1}$, respectively. It is worthy noted that caffeine and acetaminophen could be mainly used in the urban areas by human and could be well degraded throughout the wastewater treatment process (Daneshvar et al., 2012; Kurissery et al., 2012; Kuroda et al., 2012). Therefore, the elevated inputs of these compounds in the drainage systems and Wu River can be attributed to the untreated municipal wastewater in these areas. In addition, the Wu River and drainage systems from the central aquatic system were the highest contributors to total CEC discharges at 52.1 (6.35 mg/1000 inhabitants per day) and $76.5 \mathrm{~g}$ $\mathrm{d}^{-1}(68.6 \mathrm{mg} / 1000$ inhabitants per day), respectively, and correspond to locations that receive large discharges from urban Taichung. Comparing the two aquatic systems emphasizes that the Zhuoshui River contributed the highest mass loading for ampicillin ( $0.84 \mathrm{mg} / 1000$ pigs per day, $51 \%$ of total mass loadings). It is noteworthy that the highest mass loading of antibiotics may be attributed to the thriving animal husbandry sector within the drainage basin of the Zhuoshui River.

\subsection{Pharmaco-signature and source contribution of CECs}

\subsubsection{Cluster analysis}

Comprehensive data analysis was carried out, covering the entire geographical area of the two aquatic systems. Fingerprinting and a dendrogram 
of the sampling points obtained via hierarchical cluster analysis are shown in Figure 5. Two well-differentiated clusters were observed: (I) a cluster containing sampling sites with high compositional fractions of caffeine and illicit drugs in the canal, drainage systems, and rivers flow through dense population areas; and (II) a cluster formed by two subclusters (A and B),characterized by relatively high compositional fractions of ampicillin and analgesics respectively.

Cluster I is the largest, formed from all sampling sites in the Tainan Canal (C1-C5), the drainage systems (LIC and LYC), the Wu (W1-W8) and Agongdian (A2-A4) Rivers, the downstream reaches of the Yanshuei River (Y3-Y6), and station E8. This cluster is defined by domestic contributions to the catchment areas as a result of high population density. Cluster II includes sampling sites on the Zhuoshui River (Z1-Z7), the Erren River (E1-E7), and stations Y1 and Y2. This cluster has high concentration, mostly of ampicillin (see Fig. 3). We recently reported high concentrations of ampicillin in areas adjacent to estuaries of the Erren River (Jiang et al., 2014). Together with these findings, it is likely that the local animal husbandry sector is responsible for the elevated levels of antibiotics. The dendrogram reveals that cluster II can be divided into two subclusters, with different patterns. High concentrations of analgesics and moderate concentrations of ampicillin merged into subcluster A (Y2, E4, E5, E6, and E7), while those with high concentrations of ampicillin only were grouped in subcluster B (Z1, Z2, Z3, Z4, Z5, Z6, Z7, Y1, E1, E2, and E3). Cluster analysis provided an estimate of source profiles for poorly characterized sampling sites. If a poorly characterized site merges with a group of sampling sites of known 
source type or types, the poorly characterized site is likely to be influenced by similar sources (Wongphatarakul et al., 1998). The cluster analysis shows that when subcluster A merged with subcluster B into cluster II, the linkage distances were small on the dendrogram, indicating high similarity. Local animal husbandry is a known source of CECs for the sampling sites on the Zhuoshui and Erren Rivers. Although no definitive explanation can be given at this stage, it is probable that the effects of antibiotic usage are also present at sampling sites of subcluster B.

\subsubsection{PCA-MLR analysis}

The pharmaco-signature and source contributions were further resolved by principal component analysis, followed by multiple linear regression (PCA-MLR). The compounds used for PCA-MLR are shown in Table 2 (undetected CECs are not shown). Four principal components (PC1, PC2, PC3, and PC4) emerged after varimax rotation, with the components accounting for $34.4 \%, 23.6 \%, 12.7 \%$, and $8.87 \%$ of the total variance, respectively. The first rotated component (PC1) is predominantly associated with acetaminophen, diclofenac, ibuprofen, naproxen, salicylic acid, caffeine, clofibric acid, gemfibrozil, and carbamazepine, which are important chemicals used in human pharmaceuticals. Thus, PC1 appears to be indicative of human pharmaceutical use and domestic discharge to aquatic systems. The second rotated component (PC2) was characterized by high loadings of four antibiotics: sulfamethoxazole, ampicillin, tetracycline, and erythromycin- $\mathrm{H}_{2} \mathrm{O}$. Chang et al. (2003) investigated overall antibiotic 
consumption in both human and animals in Taiwan. Annual consumption of antibiotics for human-use is estimated at only 378 tons, while 1040 tons is estimated for animal-use antibiotics in animal husbandry. This indicates that animal-use antibiotics account for $76 \%$ of the total quantity of antibiotics consumed, suggesting that consumption of antibiotics in Taiwan is mainly for animal-use. Based on this profile, antibiotics application in animal husbandry area was speculated to be the potential source (Jiang et al., 2014; Jiang et al., 2015a). The profile of the third rotated component (PC3) shows high loadings of ketoprofen, codeine, methamphetamine, ketamine, and pseudoephedrine. These chemicals derive mainly from illicit drug use, although some may partially derive from medical usage in hospitals. Thus, it would be useful to ascertain the proportions of these drugs derived from legitimate medical uses as compared to illicit drug use. PC4 correlated only with UV filters (benzophenone-3 and benzophenone-4). Because these compounds are used mostly as an ingredient in sunscreen, PC4 represents applications associated with UV filters.

Multiple linear regression analysis of elements in the factor scores matrix $\left(\mathrm{FS}_{k}\right)$ against the normal standard deviate of the sum CEC values $\left(\hat{Z}_{\text {sum }}\right)$ was performed on the PCA scores to determine the mass apportionment of the four components in all samples from the two aquatic systems, giving Eq. 4:

$$
\hat{Z}_{\text {sum }}=0.905 F S_{1}+0.249 F S_{2}+0.329 F S_{3}\left(R^{2}=0.989\right)
$$

By expanding $\hat{Z}_{\text {sum }}$, the MLR equation can be written as:

$$
Z_{\text {sum }}=0.905 \quad F S_{1}+0.249 \quad F S_{2}+0.329 \quad F S_{3}+\text { mean }\left[Z_{\text {sum }}\right]
$$

where is $3087 \mathrm{ng} \mathrm{L}^{-1}$; and mean $\left[Z_{\text {sum }}\right]$ is $1750 \mathrm{ng} \mathrm{L}^{-1}$. Thus, the analysis 
demonstrated that the first three components (PC1, PC2, and PC3) were retained, and the percentage contributions $\left(B_{k} / \quad B_{k}\right)$ were $61.0 \%$ for domestic inputs (Factor 1), 16.8\% for antibiotics application (Factor 2), and $22.2 \%$ for drug abuse/medication (Factor 3). Figure 6 illustrates the estimated contributions of each source to the two aquatic systems: the CEC contributions to stations E1 and $\mathrm{Z} 1$ were very low, further supporting the idea that these areas of sparse population had no important input source into. PCA-MLR analysis showed that the source contributions in the drainage systems, the Wu River, Tainan Canal, and the Agongdian River were relatively high, with substantial domestic inputs (FS 1 ; suggesting that domestic sewage discharge is the main pharmaco-signature of CECs in these areas. The contributions due to $\mathrm{FS}_{2}$ were relatively low, except for sampling sites influenced by animal husbandry, indicating the pharmaco-signature of antibiotics used in animal husbandry as a significant source of antibiotic contamination in Zhuoshui River and Erren River watersheds. The contributions from $\mathrm{FS}_{3}$ were relatively high in Tainan Canal and downstream reaches of the Yanshuei River (Y4 and Y5) in the southern aquatic system, and in the Wu River (W2-W7) and drainage systems in the central aquatic system. This is likely because the sampling sites are close to regions with high population density and high legal/illegal consumption of drugs.

Our previous study demonstrated that seasonal variation in CEC concentrations can be observed when rainfall dilutes surface waters, but that no distinct difference is found in the seasonal variation of the pharmaco-signature in water systems (Jiang et al., 2015a). Therefore, although the present study did not 
collect samples in different seasons, the representative pharmaco-signature and source contribution can be estimated for both central and southern aquatic systems. It should be noted that grab sampling was employed in this study though suffering from the known limitation. It is also important for researcher that not only should strive to include indicative source markers and more representative data, but also further improvements are required in future study to obtain a convincing result and appropriate sampling via employment of the composite samplers. Therefore, it could make pharmaco-signature more applicable for environmental studies to further resolve potential source contributions and identification. In general, relatively high percentage of antibiotics application was observed in Zhuoshui River (66-89\%) and Erren River (1.8-74\%), while high percentage of domestic inputs and drug abuse/medication were found in Wu River (49-76\% and 15-42\%), drainage systems (77-81\% and 13-21\%), Tainan Canal (40-79\% and 19-56\%), and Agongdian River (69-79\% and 14-24\%). These results may be consistent with land-use structure (residential areas/husbandry areas) in each river basin. Moreover, it is interesting to compare the CEC source contributions from different aquatic systems. In this study, mean percentage contributions to sources in the southern aquatic system were $62.2 \%$ for domestic inputs, $16.9 \%$ for antibiotics application, and 20.9\% for drug abuse/medication, compared with 47.3\% of the mean summed CECs from domestic inputs, 35.1\% from antibiotics, and $17.6 \%$ from drug abuse/medication in the central aquatic system. Our previous study found that the mean percentage contributions to the catchment in 
Kaohsiung were 59.9\% from domestic sources, 19.6\% from antibiotic applications, and 20.5\% from drug abuse/medication (Jiang et al., 2015a). Considered together, these findings imply that aquatic systems in southern Taiwan (Tainan and Kaohsiung) are extensively contaminated by medical pharmaceuticals present in domestic discharges, while the contribution of antibiotics to pharmaco-signature was two times higher in central Taiwan (Taichung). The results could provide further information for strategies on environmental management.

\section{Acknowledgments}

The financial support of the Ministry of Science and Technology (MOST 102-2611-M-110-009 and 100-2611-M-110-010), and the Ministry of Education of Taiwan (DOE 04C030201 and DOE 01C030203) is gratefully acknowledged. We are indebted to Bo-Wen Tu for invaluable assistance with sample collection. This study was also partially supported by Aim for the Top University Grant from Kaohsiung Medical University (Grant No. KMU-TP103A27)." We express our gratitude to the three anonymous reviewers who helped considerably improving this manuscript.

\section{Appendix A. Supplementary data}

Supplementary data related to this article can be found at

\section{References}


Bu, Q.W., Wang, B., Huang, J., Deng, S.B., Yu, G., 2013. Pharmaceuticals and personal care products in the aquatic environment in China: A review. J. Hazard. Mater. 262, 189-211.

Carmona, E., Andreu, V., Pico, Y., 2014. Occurrence of acidic pharmaceuticals and personal care products in Tuna River Basin: From waste to drinking water. Sci. Total Environ. 484, 53-63.

Chang, H., Wan, Y., Hu, J.Y., 2009. Determination and source apportionment of five classes of steroid hormones in urban rivers. Environ. Sci. Technol. 43, 7691-7698.

Chang, S.C., Chen, M.W., Lin, M.C., Hu, O.Y.P., 2003. Antibiotic consumption in human and animals in Taiwan. Infection Control Journal 13, 334-345.

COA, Council of Agriculture, Executive Yuan, Taiwan. Available: http://www.fa.gov.tw. Accessed 2012.

Daneshvar, A., Aboulfadl, K., Viglino, L., Broseus, R., Sauve, S., Madoux-Humery, A.S., Weyhenmeyer, G.A., Prevost, M., 2012. Evaluating pharmaceuticals and caffeine as indicators of fecal contamination in drinking water sources of the Greater Montreal region. Chemosphere 88, 131-139.

Gonzalez, S., Lopez-Roldan, R., Cortina, J.L., 2012. Presence and biological effects of emerging contaminants in Llobregat River basin: A review. Environ. Pollut. $161,83-92$.

Heeb, F., Singer, H., Pernet-Coudrier, B., Qi, W.X., Liu, H.J., Longree, P., Muller, B., Berg, M., 2012. Organic micropollutants in rivers downstream of the megacity Beijing: Sources and mass fluxes in a large-scale wastewater irrigation system. Environ. Sci. Technol. 46, 8680-8688.

Hernando, M.D., Mezcua, M., Fernandez-Alba, A.R., Barcelo, D., 2006.

Environmental risk assessment of pharmaceutical residues in wastewater effluents, surface waters and sediments. Talanta 69, 334-342.

Hoerger, C.C., Akhtman, Y., Martelletti, L., Rutler, R., Bonvin, F., Grange, A., Arey, J.S., Kohn, T., 2014. Spatial extent and ecotoxicological risk assessment of a micropollutant-contaminated wastewater plume in Lake Geneva. Aquat. Sci. 76, S7-S19.

Hopke, P.K., 2003. Recent developments in receptor modeling. J. Chemometr. 17, 255-265.

Jiang, J.J., Lee, C.L., Fang, M.D., 2014. Emerging organic contaminants in coastal waters: Anthropogenic impact, environmental release and ecological risk. Mar. 
Pollut. Bull. 85, 391-399.

Jiang, J.J., Lee, C.L., Fang, M.D., Boyd, K.G., Gibb, S.W., 2015a. Source apportionment and risk assessment of emerging contaminants: An approach of pharmaco-signature in water systems. PLoS One 10, e0122813.

Jiang, J.J., Lee, C.L., Fang, M.D., Tu, B.W., Liang, Y.J., 2015b. Impacts of emerging contaminants on surrounding aquatic environment from a youth festival.

Environ. Sci. Technol. 49, 792-799.

Kasprzyk-Hordern, B., Dinsdale, R.M., Guwy, A.J., 2008. The occurrence of pharmaceuticals, personal care products, endocrine disruptors and illicit drugs in surface water in South Wales, UK. Water Res. 42, 3498-3518.

Kolpin, D.W., Furlong, E.T., Meyer, M.T., Thurman, E.M., Zaugg, S.D., Barber, L.B., Buxton, H.T., 2002. Pharmaceuticals, hormones, and other organic wastewater contaminants in US streams, 1999-2000: A national reconnaissance. Environ. Sci. Technol. 36, 1202-1211.

Kurissery, S., Kanavillil, N., Verenitch, S., Mazumder, A., 2012. Caffeine as an anthropogenic marker of domestic waste: A study from Lake Simcoe watershed. Ecological Indicators 23, 501-508.

Kuroda, K., Murakami, M., Oguma, K., Muramatsu, Y., Takada, H., Taldzawa, S., 2012. Assessment of groundwater pollution in Tokyo using PPCPs as sewage markers. Environ. Sci. Technol. 46, 1455-1464.

Larsen, R.K., Baker, J.E., 2003. Source apportionment of polycyclic aromatic hydrocarbons in the urban atmosphere: A comparison of three methods. Environ. Sci. Technol. 37, 1873-1881.

Loos, R., Carvalho, R., Antonio, D.C., Cornero, S., Locoro, G., Tavazzi, S., Paracchini, B., Ghiani, M., Lettieri, T., Blaha, L., Jarosova, B., Voorspoels, S., Servaes, K., Haglund, P., Fick, J., Lindberg, R.H., Schwesig, D., Gawlik, B.M., 2013. EU-wide monitoring survey on emerging polar organic contaminants in wastewater treatment plant effluents. Water Res. 47, 6475-6487.

Luo, Y.L., Guo, W.S., Ngo, H.H., Nghiem, L.D., Hai, F.I., Zhang, J., Liang, S., Wang, X.C.C., 2014. A review on the occurrence of micropollutants in the aquatic environment and their fate and removal during wastewater treatment. Sci. Total Environ. 473, 619-641.

Michael, I., Rizzo, L., McArdell, C.S., Manaia, C.M., Merlin, C., Schwartz, T., Dagot, C., Fatta-Kassinos, D., 2013. Urban wastewater treatment plants as hotspots for the release of antibiotics in the environment: A review. Water Res. 47, 
957-995.

Nakada, N., Komori, K., Suzuki, Y., Konishi, C., Houwa, I., Tanaka, H., 2007. Occurrence of 70 pharmaceutical and personal care products in Tone River basin in Japan. Water Sci. Technol. 56, 133-140.

Phillips, P.J., Smith, S.G., Kolpin, D.W., Zaugg, S.D., Buxton, H.T., Furlong, E.T., Esposito, K., Stinson, B., 2010. Pharmaceutical formulation facilities as sources of opioids and other pharmaceuticals to wastewater treatment plant effluents. Environ. Sci. Technol. 44, 4910-4916.

Postigo, C., de Alda, M.J.L., Barcelo, D., 2010. Drugs of abuse and their metabolites in the Ebro River basin: Occurrence in sewage and surface water, sewage treatment plants removal efficiency, and collective drug usage estimation. Environ. Int. 36, 75-84.

Sanchez-Avila, J., Tauler, R., Lacorte, S., 2012. Organic micropollutants in coastal waters from NW Mediterranean Sea: Sources distribution and potential risk. Environ. Int. 46, 50-62.

Schwarzenbach, R.P., Escher, B.I., Fenner, K., Hofstetter, T.B., Johnson, C.A., von Gunten, U., Wehrli, B., 2006. The challenge of micropollutants in aquatic systems. Science 313, 1072-1077.

Thomas, K.V., Bijlsma, L., Castiglioni, S., Covaci, A., Emke, E., Grabic, R., Hernandez, F., Karolak, S., Kasprzyk-Hordern, B., Lindberg, R.H., de Alda, M.L., Meierjohann, A., Ort, C., Pico, Y., Quintana, J.B., Reid, M., Rieckermann, J., Terzic, S., van Nuijs, A.L.N., de Voogt, P., 2012. Comparing illicit drug use in 19 European cities through sewage analysis. Sci. Total Environ. 432, 432-439.

TWFDA, Food and Drug Administration, Department of Health, Excutive Yuan, Taiwan. Available: http://www.fda.gov.tw. Accessed 2012.

UNWPP, 2013. World Population Prospects: The 2012 Revision. Population Division, Department of Economic and Social Affairs, United Nations. Available from: http://esa.un.org/wpp/Documentation/publications.htm.

Verlicchi, P., Al Aukidy, M., Zambello, E., 2012. Occurrence of pharmaceutical compounds in urban wastewater: Removal, mass load and environmental risk after a secondary treatment-A review. Sci. Total Environ. 429, 123-155.

Vidal-Dorsch, D.E., Bay, S.M., Maruya, K., Snyder, S.A., Trenholm, R.A., Vanderford, B.J., 2012. Contaminants of emerging concern in municipal wastewater effluents and marine receiving water. Environ. Toxicol. Chem. 31, 
2674-2682.

Wongphatarakul, V., Friedlander, S.K., Pinto, J.P., 1998. A comparative study of PM2.5 ambient aerosol chemical databases. Environ. Sci. Technol. 32, 3926-3934.

Xue, B.M., Zhang, R.J., Wang, Y.H., Liu, X., Li, J., Zhang, G., 2013. Antibiotic contamination in a typical developing city in south China: Occurrence and ecological risks in the Yongjiang River impacted by tributary discharge and anthropogenic activities. Ecotox. Environ. Safe. 92, 229-236.

Yoon, Y., Ryu, J., Oh, J., Choi, B.G., Snyder, S.A., 2010. Occurrence of endocrine disrupting compounds, pharmaceuticals, and personal care products in the Han River (Seoul, South Korea). Sci. Total Environ. 408, 636-643.

Zhu, S.C., Chen, H., Li, J.N., 2013. Sources, distribution and potential risks of pharmaceuticals and personal care products in Qingshan Lake basin, Eastern China. Ecotox. Environ. Safe. 96, 154-159.

\section{Figure captions}

Figure 1. Location of sampling sites in catchments associated with Tainan and Taichung, Taiwan. Southern aquatic system: Yanshuei River (Y1-Y6); Tainan Canal (C1-C5); Erren River (E1-E8); Agongdian River (A1-A4). Central aquatic system: Wu River (W1-W8); Zhuoshui River (Z1-Z7); LIC and LYC are drainage systems. The values in blue boxes show population density.

Figure 2. Concentration ranges of CECs in all samples. Those for the southern aquatic systems are shown in dark blue, and for the central aquatic systems are in light blue. The solid bar shows the median and the box denotes the 0.25 and 0.75 percentiles. The whiskers mark the last value within a range of 1.5 times the 0.25 and 0.75 percentiles. Outliers are marked by dots.

Figure 3. CEC concentrations (mean) in the two aquatic systems. Other pharmaceuticals include clofibric acid, gemfibrozil, and carbamazepine.

Figure 4. Mass loadings of CECs from the aquatic systems. 
Figure 5. Hierarchical cluster analysis and compositional patterns of CECs in the two aquatic systems.

Figure 6. PCA-MLR source contribution plots for the two aquatic systems. FS1: domestic inputs; FS2: antibiotic application; FS3: drug abuse/medication. 


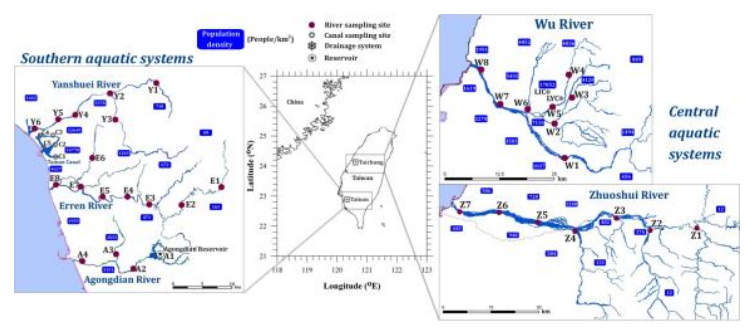




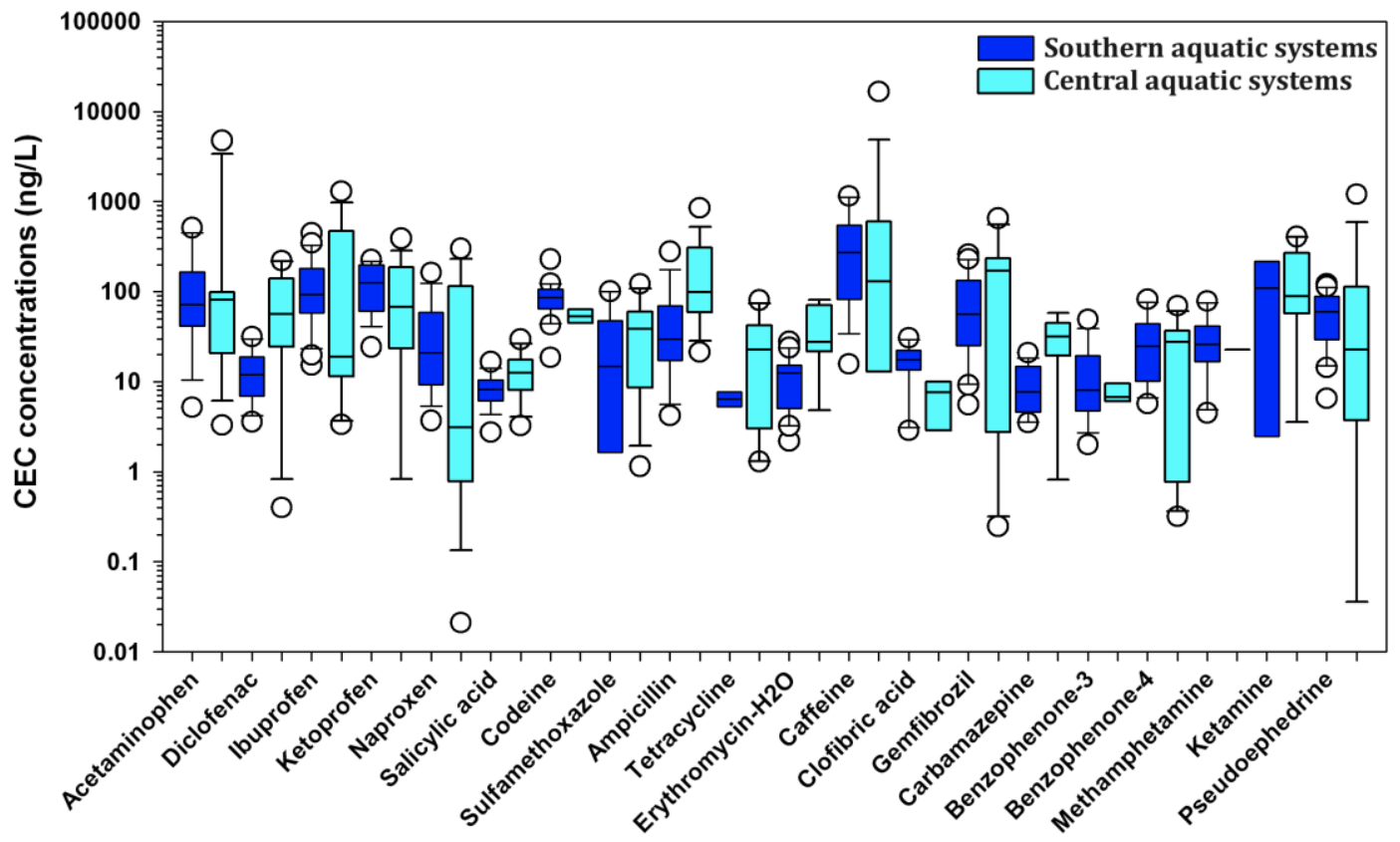




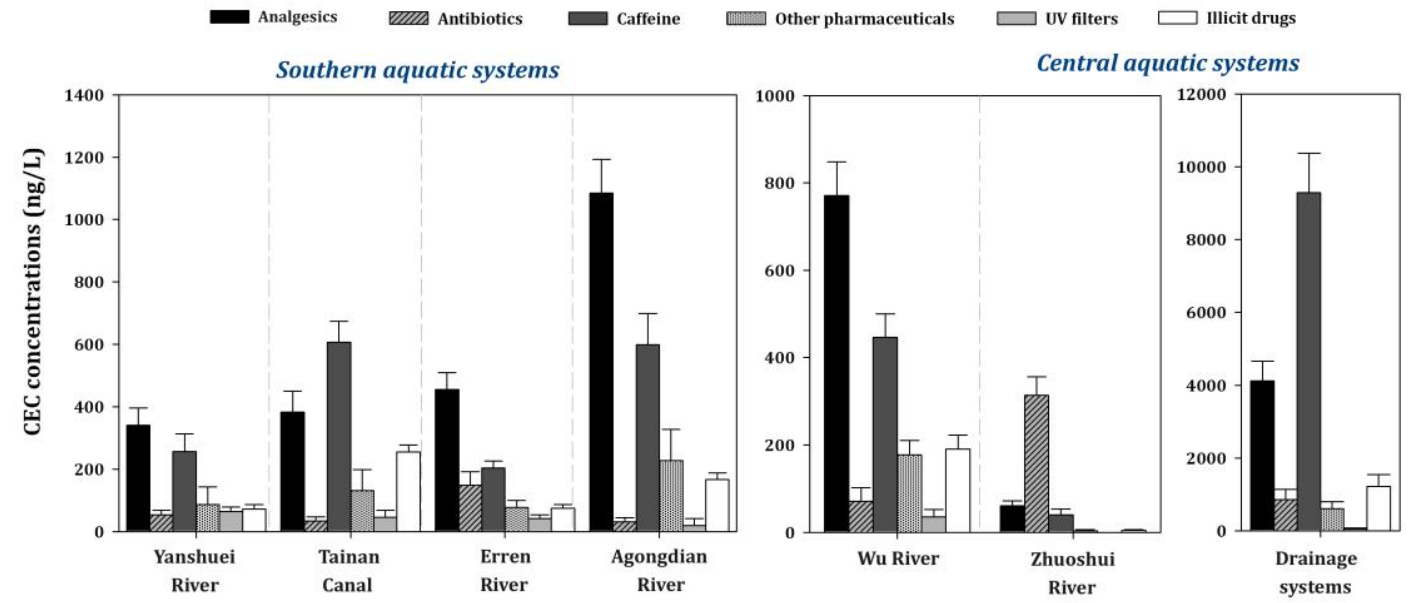




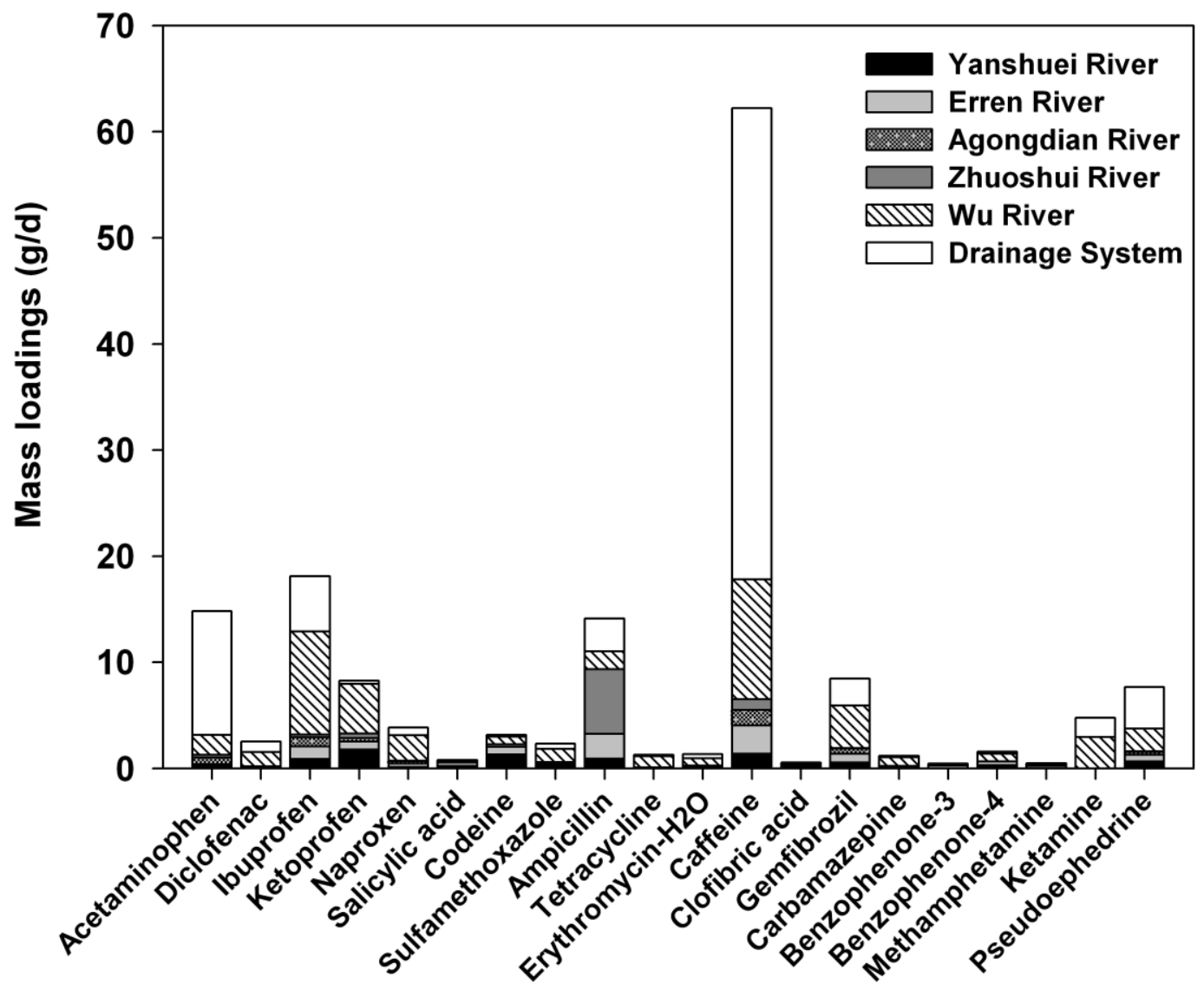




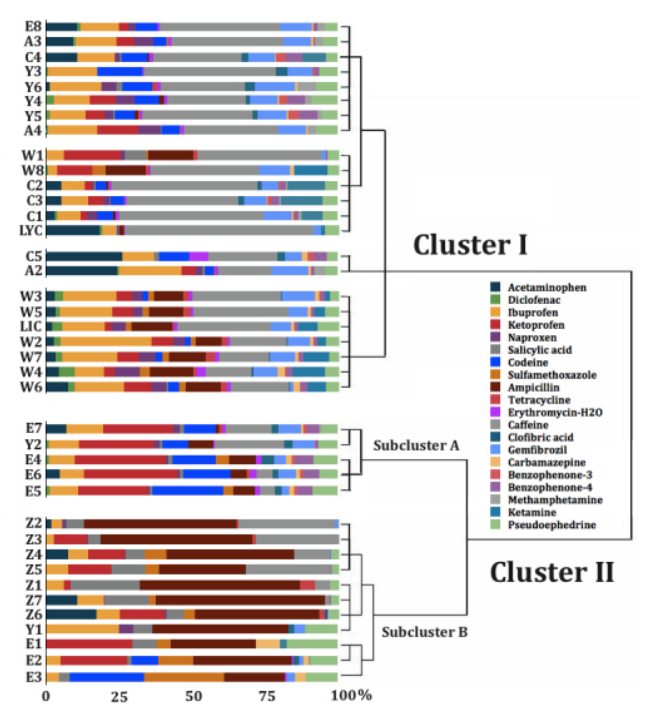



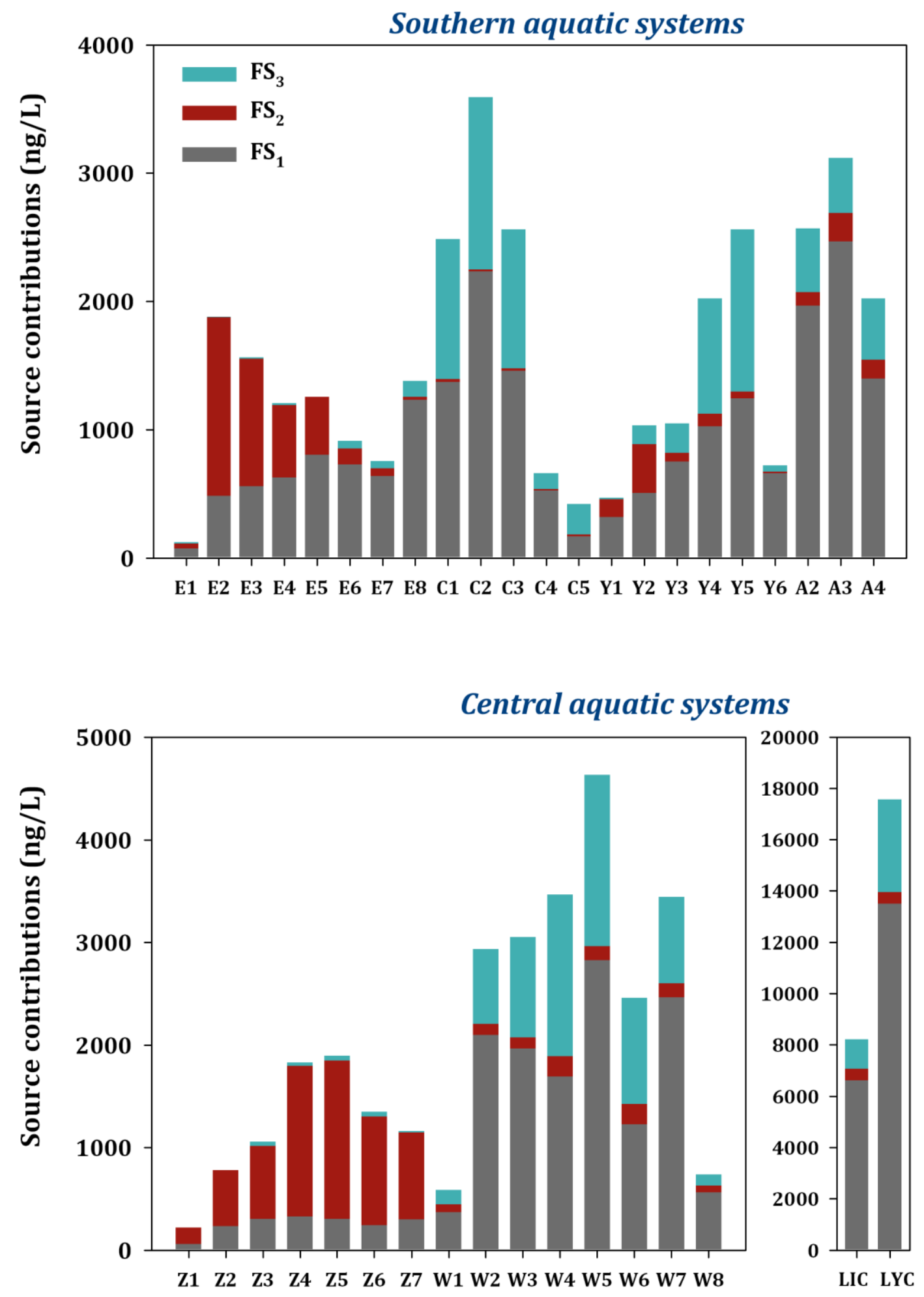
Table 1. Geographical information for the southern and central aquatic systems.

\begin{tabular}{|c|c|c|c|c|c|c|c|}
\hline River & $\begin{array}{l}\text { Length } \\
(\mathrm{km})\end{array}$ & $\begin{array}{c}\text { Drainage } \\
\text { area }\end{array}$ & $\begin{array}{l}\text { Annual } \\
\text { rainfall }\end{array}$ & $\begin{array}{l}\text { Flow rate } \\
\left(\mathrm{m}^{3} / \mathrm{d}\right)^{\mathrm{a}}\end{array}$ & $\begin{array}{c}\text { Population per } \\
\text { unit area }\end{array}$ & $\begin{array}{c}\text { Pig per unit } \\
\text { area }\end{array}$ & WWTPs b \\
\hline \multicolumn{8}{|c|}{ Southern aquatic systems } \\
\hline $\begin{array}{l}\text { Yanshuei } \\
\text { River }\end{array}$ & 41.3 & 343.7 & 1650 & $2,083,968$ & 1955 & 209 & - \\
\hline $\begin{array}{l}\text { Tainan } \\
\text { Canal }\end{array}$ & 5 & NA & NA & NA & 6410 & NA & $\begin{array}{c}1 \text { (Primary + } \\
\text { Secondary } \\
\text { treatment) }\end{array}$ \\
\hline $\begin{array}{l}\text { Erren } \\
\text { River }\end{array}$ & 61.2 & 339.2 & 1850 & $1,678,752$ & 1006 & 649 & - \\
\hline $\begin{array}{l}\text { Agongdian } \\
\text { River }\end{array}$ & 38 & 137 & 1730 & 819,936 & 1728 & 123 & - \\
\hline \multicolumn{8}{|c|}{ Central aquatic systems } \\
\hline Wu River & 117 & 2026 & 1800 & $3,620,160$ & 4052 & 4 & $\begin{array}{c}1 \text { (Primary + } \\
\text { Secondary } \\
\text { treatment) }\end{array}$ \\
\hline $\begin{array}{l}\text { Zhuoshui } \\
\text { River }\end{array}$ & 187 & 3155 & 2200 & $4,086,720$ & 471 & 716 & - \\
\hline
\end{tabular}

Data obtained from Taiwan Water Resources Agency and Council of Agriculture.

a Mean fluxes at each river.

b Wastewater treatment plants.

NA: Information was not available. 
Table 2. Varimax-rotated component matrix following principal component analysis of all water samples.

\begin{tabular}{|c|c|c|c|c|}
\hline \multirow{2}{*}{ Variable } & \multicolumn{4}{|c|}{ Rotated component number } \\
\hline & 1 & 2 & 3 & 4 \\
\hline Acetaminophen & 0.954 & 0.142 & 0.172 & -0.046 \\
\hline Diclofenac & 0.813 & 0.480 & 0.100 & 0.147 \\
\hline Ibuprofen & 0.694 & 0.565 & 0.291 & 0.052 \\
\hline Ketoprofen & 0.375 & -0.173 & 0.623 & 0.076 \\
\hline Naproxen & 0.858 & -0.211 & 0.351 & 0.152 \\
\hline Salicylic acid & 0.713 & -0.284 & -0.249 & -0.234 \\
\hline Codeine & 0.274 & 0.115 & 0.613 & 0.438 \\
\hline Sulfamethoxazole & 0.339 & 0.747 & -0.225 & -0.052 \\
\hline Ampicillin & 0.288 & 0.897 & -0.198 & 0.024 \\
\hline Tetracycline & 0.002 & 0.753 & -0.112 & -0.094 \\
\hline Erythromycin- $\mathrm{H}_{2} \mathrm{O}$ & 0.406 & 0.818 & 0.240 & 0.222 \\
\hline Caffeine & 0.941 & 0.210 & 0.161 & 0.016 \\
\hline Clofibric acid & 0.805 & -0.014 & -0.278 & 0.305 \\
\hline Gemfibrozil & 0.616 & 0.485 & 0.461 & 0.163 \\
\hline Carbamazepine & 0.910 & -0.208 & 0.049 & 0.066 \\
\hline Benzophenone-3 & 0.015 & -0.035 & 0.187 & 0.897 \\
\hline Benzophenone-4 & 0.434 & -0.018 & 0.094 & 0.787 \\
\hline Methamphetamine & -0.062 & 0.253 & 0.895 & 0.005 \\
\hline Ketamine & 0.482 & 0.435 & 0.908 & 0.264 \\
\hline Pseudoephedrine & 0.397 & -0.184 & 0.882 & 0.087 \\
\hline $\begin{array}{l}\text { Percentage variance explained } \\
(\%)\end{array}$ & 34.3 & 23.6 & 12.7 & 8.87 \\
\hline
\end{tabular}

Extraction method: Principal component analysis.

Rotation method: Varimax with Kaiser normalization. 